\title{
Adipose cell and lipid turnovers in obesity and insulin resistance
}

\author{
Tetsuro Izumi
}

Received: 24 July 2012/ Accepted: 27 July 2012/Published online: 22 August 2012

(C) The Japan Diabetes Society 2012

The correlation between the twin epidemics of obesity and insulin resistance is well established on a population level. However, the association between the degree of obesity and the development of insulin resistance is less obvious at the individual level, although there should be a mechanistic link that specifically and differentially connects the two conditions. To identify such a link, we must first understand the process of change in vivo in adipocyte number and volume and the regulation of lipid storage and removal in both lean and obese individuals. Obesity, characterized by expanded fat mass, may involve both an increased volume of preexisting adipocytes (hypertrophy) and the generation of new adipocytes (hyperplasia). Whereas methods for measuring the size of fat cells are available, it is more difficult to determine their total number, which can be estimated by dividing total body fat weight by mean adipose cell weight calculated from mean cell diameter [1]. However, the dynamics of fat cell turnover in vivo have not been sufficiently studied. Spalding, Arner, and collaborators [2] investigated these dynamics in humans by measuring the incorporation of atmospheric carbon $14\left({ }^{14} \mathrm{C}\right)$ into genomic DNA. They took advantage of the fact that ${ }^{14} \mathrm{C}$ levels in the atmosphere transiently increased during above-ground nuclear bomb tests between 1955 and 1963 and exponentially decreased after cessation of the tests. ${ }^{14} \mathrm{C}$ in the atmosphere oxidizes to form carbon dioxide $\left(\mathrm{CO}_{2}\right)$, which is taken up into organic components during plant photosynthesis. Because humans eat plants, or animals that live off

T. Izumi $(\square)$

Laboratory of Molecular Endocrinology and Metabolism, Department of Molecular Medicine, Institute for Molecular and Cellular Regulation, Gunma University,

3-39-15 Showa-machi, Maebashi, Gunma 371-8512, Japan

e-mail: tizumi@showa.gunma-u.ac.jp plants, the ${ }^{14} \mathrm{C}$ content in the human body parallels that in the atmosphere and can be used to calculate the turnover rate of adipocytes. The study authors first confirmed that adipocyte number in individuals with early onset of obesity is higher than in lean individuals. They then demonstrated that $8.4 \%$ of fat cells are renewed annually at all adult ages and levels of body mass index (BMI). Nevertheless, the adipocyte number stays remarkably constant in adulthood in both lean and obese individuals, which indicates that there should be a mechanism to closely balance their birth and death rates, even in the obese, and that the difference in adipocyte number between lean and obese individuals is established during childhood. In support of this, Spalding et al. found no significant difference in the average age of adipocytes in lean versus obese individuals. Therefore, hyperplastic obesity, which is most marked in early-onset, severely obese individuals [3, 4], is determined by genetic factors or by nutrient states in childhood. These findings also suggest that weight change in adulthood is primarily the result of changes in adipocyte volume. It was reported that in a population-based sample, adipocyte hypertrophy is associated with decreased insulin sensitivity, even in lean and apparently healthy individuals [5]. This may be relevant to the hypothesis that larger adipocytes secrete proportionally more proinflammatory adipocytokines than antiinflammatory adipocytokines compared with smaller adipocytes, as was previously reported [6].

Very recently, Arner et al. [7] determined the human adipose lipid turnover by measuring the incorporation of atmospheric ${ }^{14} \mathrm{C}$ into adipocyte triglyceride (TG). They demonstrated that adipose lipids are also dynamic: TG is renewed six times (mean adipocyte lipid age 1.6 years) during the average lifespan of human adipocytes (9.5 years). Lipid age is independent of adipocyte size and is highly stable across a wide range of adult ages. Thus, lipid 
age, as was seen in adipocyte age, is fixed during childhood. Lipid age determined by ${ }^{14} \mathrm{C}$ measurement is inversely correlated with lipid removal rate, which represents the hydrolysis of TG (lipolysis) followed by the irreversible removal of lipids by oxidation in peripheral tissues. Because the removal rate is dependent on total fat mass, the net lipid storage per year (the rate of lipid uptake) can be determined by the lipid removal rate and the total fat mass. Surprisingly, the authors found that the lipid removal rate rather than lipid storage rate is most strongly related to insulin resistance in conditions with disturbed lipid metabolism, despite the fact that lipid age is independent of adipocyte size [7]. In obese individuals, the rate of TG storage and mean lipid age (inverse of turnover rate) were markedly increased compared with nonobese individuals. On the other hand, in nonobese individuals with familial combined hyperlipidemia, the most common hereditary form of dyslipidemia, lipid age was similarly increased, as was found in obesity, but the rate of TG storage was markedly decreased compared with nonobese individuals. Therefore, in the two pathological states, lipid age, but not TG storage rate, is correlated with insulin resistance. Furthermore, even among lean healthy individuals, lipid age has an impact on wholebody insulin sensitivity. It remains to be determined just how adipocyte size (hypertrophy) impacts insulin sensitivity [5] if the lipid storage rate is unrelated to insulin sensitivity and if lipid age is unrelated to adipocyte size [7].

Arner et al. [7] also measured adipose tissue lipolysis because it represents the first step in lipid removal. Although basal lipolysis was not related to lipid turnover, the cyclic adenosine monophosphate (cAMP)-induced lipolytic rate was positively correlated with the rate of TG removal (inversely correlated with lipid age) but was not related to the rate of TG uptake (lipid storage). These findings indicate that lipolysis determines the lipid turnover rate in adipocytes and the level of insulin sensitivity in a whole body. This is somewhat counterintuitive, because increased lipolysis due to insulin resistance is conventionally thought to be responsible for the increased release of fatty acids (FAs) from adipocytes (lipolysis is induced by anti-insulin hormones, such as epinephrine, and is suppressed by insulin). Chronically elevated plasma free FAs might inhibit insulin signaling and induce ectopic TG storage in liver and skeletal muscle [8]. However, increased lipolysis itself may not necessarily cause insulin resistance for several reasons. First, sustained lipolysis eventually decreases total fat mass and thus the amount of released FAs, even though the lipolytic rate per fat mass remains high. Second, an increased supply of FAs by elevated lipolysis can be accompanied by preferential FA oxidation and may not cause ectopic TG storage in peripheral tissues. In fact, overexpression of the major adipose lipase, adipose triglyceride lipase (ATGL), in mouse adipose tissue does not increase plasma free FA levels despite increased lipolysis and improves insulin sensitivity during diet-induced obesity [9].

The above finding, that lipid removal rate rather than lipid storage rate is correlated with insulin sensitivity suggests that lipid turnover/cycling/remodeling is essential to keep adipocytes intact, thus preventing insulin resistance, and to consume lipids efficiently as an energy source at the whole-body level. In fact, decreased levels of adipocyte lipases and defective lipolysis are often found in human obesity [10-13]. It remains unknown, however, just how lipolysis affects insulin sensitivity in obese states. As discussed above, increased lipolysis eventually decreases fat-cell mass and size, which may have beneficial effects by changing adipocytokine repertoires to suppress chronic inflammation [6]. However, lipid age correlated with insulin resistance is similar in small or large adipocytes within and between individuals, which suggests a continuous exchange of lipids within adipose tissue between adipocytes of different sizes [7]. Adipose tissue re-esterifies $\sim 30 \%$ of the free FA released from TG during lipolysis [14, 15], and the re-esterification process requires energy that costs $\sim 3 \%$ of the total energetic content of a molecule of TG [16]. Although this futile cycle does not contribute to the "irreversible" removal rate of TG from adipose tissue of the sort measured in the work introduced here [7], locally inert lipid depots without the FA exchange might cause chronic inflammation and insulin resistance on the whole-body level. The re-esterification normally occurs with the supply of glycerol-3-phosphate (G-3-P), which is derived from glucose via glycolysis or from other sources such as pyruvate, lactate, and alanine via glyceroneogenesis. This is because G-3-P cannot be directly converted from glycerol due to the absence of glycerol kinase in adipocytes. Although glyceroneogenesis is generally thought to stimulate TG synthesis by antagonizing lipolysis, it may play an indirect role in stimulating lipid turnover by cycling the synthesis and breakdown of TG. Indeed, FA re-esterification is coupled to lipolysis [17], and both lipolysis and glyceroneogenesis are induced during a fast [18]. Furthermore, thiazolidinediones (TZDs), which activate peroxisome proliferator-activated receptor (PPAR)- $\gamma$ and sensitize insulin action, stimulate both lipolysis [19-23] and glyceroneogenesis [24, 25]. TZDs induce adipose expression of phosphoenolpyruvate carboxykinase, a key enzyme of glyceroneogenesis [24], and the normally absent glycerol kinase [26], both of which generate G-3-P. Although PPAR$\gamma$ induces adipogenesis during differentiation, it may also play a role in stimulating lipid turnover in mature adipocytes to improve insulin sensitivity. Consistent with this notion, we recently found that PPAR- $\gamma$ activation selectively in mature adipocytes decreases fat accumulation in sum in a mouse obesity model and in a cultured 3T3-L1 cell line, although they promote both synthesis and breakdown 
of TG [27]. In fact, a dysfunction of PPAR- $\gamma$ may well be a hallmark of obesity. If PPAR- $\gamma$ can be selectively activated in mature adipocytes, it may more efficiently improve insulin sensitivity, because weight gain, a major side effect of TZDs via brain PPAR- $\gamma$ [28, 29], may not occur.

In summary, the seminal data presented by Spalding, Arner, and collaborators [2, 7] help elucidate the mechanism by which adipose cells and lipid turnover are physiologically regulated and help identify the components that affect insulin sensitivity in pathological states. A better understanding of the molecular mechanisms controlling adipocyte and lipid turnover in vivo may lead to more effective interventions for obesity and associated insulin resistance.

\section{References}

1. Hirsch J, Gallian E. Methods for the determination of adipose cell size in man and animals. J Lipid Res. 1968;9:110-9.

2. Spalding KL, Arner E, Westermark PO, Bernard S, Buchholz BA, Bergmann O, Blomqvist L, Hoffstedt J, Näslund E, Britton T, Concha H, Hassan M, Ryden M, Frisén J, Arner P. Dynamics of fat cell turnover in humans. Nature. 2008;453:783-7.

3. Knittle JL, Timmers K, Ginsberg-Fellner F, Brown RE, Katz DP. The growth of adipose tissue in children and adolescents: crosssectional and longitudinal studies of adipose cell number and size. J Clin Invest. 1979;63:239-46.

4. Hirsch J, Batchelor B. Adipose tissue cellularity in human obesity. Clin Endocrinol Metab. 1976;5:299-311.

5. Arner E, Westermark PO, Spalding KL, Britton T, Rydén M, Frisén J, Bernard S, Arner P. Adipocyte turnover: relevance to human adipose tissue morphology. Diabetes. 2010;59:105-9.

6. Skurk T, Alberti-Huber C, Herder C, Hauner H. Relationship between adipocyte size and adipokine expression and secretion. J Clin Endocrinol Metab. 2007;92:1023-33.

7. Arner P, Bernard S, Salehpour M, Possnert G, Liebl J, Steier P, Buchholz BA, Eriksson M, Arner E, Hauner H, Skurk T, Rydén M, Frayn KN, Spalding KL. Dynamics of human adipose lipid turnover in health and metabolic disease. Nature. 2011;478:110-3.

8. Boden G, Shulman GI. Free fatty acids in obesity and type 2 diabetes: defining their role in the development of insulin resistance and $\beta$-cell dysfunction. Eur J Clin Invest. 2002;32(Suppl 3): $14-23$.

9. Ahmadian M, Duncan RE, Varady KA, Frasson D, Hellerstein MK, Birkenfeld AL, Samuel VT, Shulman GI, Wang Y, Kang C, Sul HS. Adipose overexpression of desnutrin promotes fatty acid use and attenuates diet-induced obesity. Diabetes. 2009;58:855-66.

10. Jensen MD, Haymond MW, Rizza RA, Cryer PE, Miles JM. Influence of body fat distribution on free fatty acid metabolism in obesity. J Clin Invest. 1989;83:1168-73.

11. Bougnères $\mathrm{P}$, Stunff $\mathrm{CL}$, Pecqueur $\mathrm{C}$, Pinglier E, Adnot $\mathrm{P}$, Ricquier D. In vivo resistance of lipolysis to epinephrine: a new feature of childhood onset obesity. J Clin Invest. 1997;99: 2568-73.

12. Langin D, Dicker A, Tavernier G, Hoffstedt J, Mairal A, Rydén M, Arner E, Sicard A, Jenkins CM, Viguerie N, van Harmelen V, Gross RW, Holm C, Arner P. Adipocyte lipases and defect of lipolysis in human obesity. Diabetes. 2005;54:3190-7.
13. Jocken JW, Langin D, Smit E, Saris WH, Valle C, Hul GB, Holm C, Arner P, Blaak EE. Adipose triglyceride lipase and hormonesensitive lipase protein expression is decreased in the obese insulin-resistant state. J Clin Endocrinol Metab. 2007;92:2292-9.

14. Vaughan M. The production and release of glycerol by adipose tissue incubated in vitro. J Biol Chem. 1962;237:3354-8.

15. van Harmelen V, Reynisdottir S, Cianflone K, Degerman E, Hoffstedt J, Nilsell K, Sniderman A, Arner P. Mechanisms involved in the regulation of free fatty acid release from isolated human fat cells by acylation-stimulating protein and insulin. J Biol Chem. 1999;274:18243-51.

16. Nye C, Kim J, Kalhan SC, Hanson RW. Reassessing triglyceride synthesis in adipose tissue. Trends Endocrinol Metab. 2008;19: 356-61.

17. Bezaire V, Mairal A, Ribet C, Lefort C, Girousse A, Jocken J, Laurencikiene J, Anesia R, Rodriguez AM, Ryden M, Stenson BM, Dani C, Ailhaud G, Arner P, Langin D. Contribution of adipose triglyceride lipase and hormone-sensitive lipase to lipolysis in hMADS adipocytes. J Biol Chem. 2009;284:18282-91.

18. Jensen MD, Ekberg K, Landau BR. Lipid metabolism during fasting. Am J Physiol Endocrinol Metab. 2001;281:E789-93.

19. Kalderon B, Mayorek N, Ben-Yaacov L, Bar-Tana J. Adipose tissue sensitization to insulin induced by troglitazone and MEDICA 16 in obese Zucker rats in vivo. Am J Physiol Endocrinol Metab. 2003;284:E795-803.

20. Festuccia WT, Laplante M, Berthiaume M, Gélinas Y, Deshaies $\mathrm{Y}$. PPAR $\gamma$ agonism increases rat adipose tissue lipolysis, expression of glyceride lipases, and the response of lipolysis to hormonal control. Diabetologia. 2006;49:2427-36.

21. Kim JY, Tillison K, Lee JH, Rearick DA, Smas CM. The adipose tissue triglyceride lipase ATGL/PNPLA2 is downregulated by insulin and $\mathrm{TNF}-\alpha$ in $3 \mathrm{~T} 3-\mathrm{L} 1$ adipocytes and is a target for transactivation by PPAR $\gamma$. Am J Physiol Endocrinol Metab. 2006;291:E115-27.

22. Kershaw EE, Schupp M, Guan HP, Gardner NP, Lazar MA, Flier JS. PPAR $\gamma$ regulates adipose triglyceride lipase in adipocytes in vitro and in vivo. Am J Physiol Endocrinol Metab. 2007;293: E1736-45.

23. Wang P, Renes J, Bouwman F, Bunschoten A, Mariman E, Keijer $\mathrm{J}$. Absence of an adipogenic effect of rosiglitazone on mature 3T3-L1 adipocytes: increase of lipid catabolism and reduction of adipokine expression. Diabetologia. 2007;50:654-65.

24. Tordjman J, Chauvet G, Quette J, Beale EG, Forest C, Antoine B. Thiazolidinediones block fatty acid release by inducing glyceroneogenesis in fat cells. J Biol Chem. 2003;278:18785-90.

25. Chen JL, Peacock E, Samady W, Turner SM, Neese RA, Hellerstein MK, Murphy EJ. Physiologic and pharmacologic factors influencing glyceroneogenic contribution to triacylglyceride glycerol measured by mass isotopomer distribution analysis. J Biol Chem. 2005;280:25396-402.

26. Guan HP, Li Y, Jensen MV, Newgard CB, Steppan CM, Lazar MA. A futile metabolic cycle activated in adipocytes by antidiabetic agents. Nat Med. 2002;8:1122-8.

27. Yogosawa S, Mizutani S, Ogawa Y, Izumi T. ALK7 suppresses lipolysis to accumulate fat in obesity through downregulation of PPAR $\gamma$ and $\mathrm{C} / \mathrm{EBP} \alpha$. Diabetes. 2012 (in press).

28. Lu M, Sarruf DA, Talukdar S, Sharma S, Li P, Bandyopadhyay G, Nalbandian S, Fan W, Gayen JR, Mahata SK, Webster NJ, Schwartz MW, Olefsky JM. Brain PPAR- $\gamma$ promotes obesity and is required for the insulin-sensitizing effect of thiazolidinediones. Nat Med. 2011;17:618-22.

29. Ryan KK, Li B, Grayson BE, Matter EK, Woods SC, Seeley RJ. A role for central nervous system PPAR- $\gamma$ in the regulation of energy balance. Nat Med. 2011;17:623-6. 